\title{
Cloud Property Retrieval from Multiband Infrared Measurements by Himawari-8
}

\author{
Hironobu IWABUCHI, Nurfiena Sagita PUTRI, Masanori SAITO, Yuka TOKORO \\ Center for Atmospheric and Oceanic Studies, Graduate School of Science, Tohoku University, Sendai, Japan
}

\section{Miho SEKIGUCHI}

The Graduate School of Marine Science and Technology, Tokyo University of Marine Science and Technology, Tokyo, Japan

Ping YANG

Department of Atmospheric Sciences, Texas A\&M University, College Station, Texas, USA

and

Bryan A. BAUM

Space Science and Engineering Center, University of Wisconsin-Madison, Wisconsin, USA

(Manuscript received 30 May 2017, in final form 30 August 2017)

\begin{abstract}
An algorithm for retrieving the macroscopic, physical, and optical properties of clouds from thermal infrared measurements is applied to the Himawari- 8 multiband observations. A sensitivity study demonstrates that the addition of the single $\mathrm{CO}_{2}$ band of Himawari-8 is effective for the estimation of cloud top height. For validation, retrieved cloud properties are compared systematically with collocated active remote sensing counterparts with small time lags. While retrievals agree reasonably for single-layer clouds, multilayer cloud systems with optically thin upper clouds overlying lower clouds are the major source of error in the present algorithm. Validation of cloud products is critical for identifying the characteristics, advantages, and limitation of each product and should be continued in the future.

As an application example, data are analyzed for eight days in the vicinity of the New Guinea to study the diurnal cycle of the cloud system. The present cloud property analysis investigates cloud evolution through separation of different cloud types and reveals typical features of diurnal cycles related to the topography. Over land, middle clouds increase from 0900 to 1200 local solar time (LST), deep convective clouds develop rapidly during 1200-1700 LST with a subsequent increase in cirrus and cirrostratus cloud amounts. Over the ocean near coastlines, a broad peak of convective cloud fraction is seen in the early morning. The present study demonstrates the utility of frequent observations by Himawari-8 for life cycle study of cloud systems, owing to the ability to capture their continuous temporal variations.
\end{abstract}

Keywords Himawari-8; cloud retrieval

Corresponding author: Hironobu Iwabuchi, Center for Atmospheric and Oceanic Studies, Graduate School of Science, Tohoku University, 6-3 Aoba, Aramakiaza, Aoba-ku, Sendai, Miyagi 980-8578, Japan

E-mail: hiroiwa@m.tohoku.ac.jp

J-stage Advance Published Date: 15 September 2017

CThe Author(s) 2018. This is an open access article published by the Meteorological Society of Japan under a Creative Commons Attribution 4.0 International (CC BY 4.0) license (http://creativecommons.org/license/by/4.0). 


\section{Introduction}

A more complete understanding of cloud-climate feedback requires a better constraint on the representation of cloud and radiation processes in regional and global climate models. The cloud radiative effect and its variations are complicated by the variety of cloud types with different cloud optical, microphysical, and macroscopic properties. Satellite remote sensing, given its ability in capturing cloud properties in a consistent and continuous form on the regional and global scales, can provide constraints on spatiotemporal variations of cloud properties and their relationships with the ambient meteorological environment. Such constraints are critical for improving the representation of the cloud dynamical and microphysical processes in the models. Operational satellite imager-based cloud products are produced by various techniques and algorithms that work on a fairly discrete range of radiometric measurements at visible (VIS) through infrared (IR) wavelengths. Other cloud products are retrieved from active radar or lidar measurements, as well as passive measurements from polarimeters, microwave, and even hyperspectral IR sensors. Before making a use of these products, it is also important to understand the differences among available satellite products, each of which has advantages and deficiencies in conjunction with specific sensors and algorithms (Waliser et al. 2009).

The Himawari- 8 satellite was launched on October 7, 2014, and is operated by the Japan Meteorological Agency since July 7, 2015. Himawari-8 is equipped with a visible infrared radiometer called the Advanced Himawari Imager (AHI), with greatly improved spectral, spatial, and temporal resolutions and better radiometric calibration, compared to previous Japanese geostationary satellites (Bessho et al. 2016). The AHI has 16 bands, including four bands in the visible and near-infrared spectrum $(0.47-0.86 \mu \mathrm{m})$, two bands in the shortwave infrared (1.6-2.3 $\mu \mathrm{m})$, one band in the medium-wave infrared $(3.9 \mu \mathrm{m})$, and nine bands in the thermal infrared (TIR) region $(5-14 \mu \mathrm{m})$. AHI observes the entire full disk of the globe every 10 minutes and the Japanese and special observation areas every 2.5 minutes. The high temporal sampling opens up the possibilities of various novel meteorological applications, including weather prediction improvement and severe weather monitoring for disaster prevention. Himawari-8 is one of the next-generation geostationary meteorological satellites and is proving to be of great benefit to both industry and the public. The Geostationary Operational Environmental Sat- ellite-16 (GOES-16), which carries the Advanced Baseline Imager (ABI) (Schmit et al. 2005), is similar to Himawari-8.

The key properties for radiation budget and hydrological cycle studies are the optical, macroscopic, and microphysical properties of clouds, including cloud cover, cloud top height $(\mathrm{CTH})$, cloud optical thickness (COT), cloud thermodynamic phase, and cloud particle effective radius (CER). Among several remote sensing methods for cloud, the TIR method is useful for uniform cloud retrievals regardless of solar illumination. The use of TIR measurements can also facilitate the retrievals for optically thin ice cloud, which can be problematic when the cloud signal is very weak. Iwabuchi et al. (2016) developed an algorithm known as the Integrated Cloud Analysis System (ICAS), which retrieves the cloud properties from measurements using 10 TIR bands of the Moderate Resolution Imaging Spectroradiometer (MODIS). The cloud analysis algorithm includes methods for the identification and property retrieval of multilayered cloud systems and the determination of cloud thermodynamic phase. The TIR method has small dependence on the assumptions of particle habits (or shapes) and surface roughness of ice crystals within the ice clouds (Cooper et al. 2006; Baum et al. 2014). The application of ICAS to the frequent observations made by Himawari-8 enables the study on cloud evolution and its life cycle from generation to dissipation and the diurnal cycle of cloud-precipitation systems with details.

This paper aims at application of the ICAS to the AHI TIR measurements, focusing on the methodology of the cloud retrieval algorithm and its validation. We also provide an example of study on cloud life cycle using the retrieved cloud properties. Section 2 describes our algorithm for estimating cloud properties, together with an error analysis and a retrieval sensitivity test to study different band combinations for $\mathrm{CTH}$ retrieval. Section 3 presents the validation results by a systematic comparison between the retrieved cloud properties with those from a radar-lidar product. A case study of diurnal cycle of cloud system in vicinity of the New Guinea is shown in Section 4. Section 5 concludes this paper with suggestions for future work.

\section{Cloud retrieval algorithm}

\subsection{General design of algorithm}

The cloud retrieval algorithm in this paper is similar to ICAS (Iwabuchi et al. 2016), but the band configuration is adjusted for application to the AHI by using eight TIR bands. Table 1 summarizes specifications of 
Table 1. AHI bands used in the cloud retrieval algorithm. Minor absorbing gases are in parentheses.

\begin{tabular}{cccl}
\hline Band & $\begin{array}{c}\text { Center } \\
\text { wavelength } \\
(\mu \mathrm{m})\end{array}$ & $\begin{array}{c}\text { Band width } \\
(\mu \mathrm{m}) \\
(\mathrm{FWHM})\end{array}$ & Absorbing gases \\
\hline 9 & 6.94 & 0.40 & $\mathrm{H}_{2} \mathrm{O}$ \\
10 & 7.35 & 0.19 & $\mathrm{H}_{2} \mathrm{O}\left(\mathrm{N}_{2} \mathrm{O}, \mathrm{CH}_{4}\right)$ \\
11 & 8.59 & 0.37 & $\left(\mathrm{H}_{2} \mathrm{O}, \mathrm{N}_{2} \mathrm{O}, \mathrm{CH}_{4}\right)$ \\
12 & 9.63 & 0.38 & $\mathrm{O}_{3}\left(\mathrm{H}_{2} \mathrm{O}, \mathrm{CO}_{2}\right)$ \\
13 & 10.4 & 0.42 & $\left(\mathrm{H}_{2} \mathrm{O}, \mathrm{CO}_{2}\right)$ \\
14 & 11.2 & 0.67 & $\left(\mathrm{H}_{2} \mathrm{O}, \mathrm{CO}_{2}\right)$ \\
15 & 12.4 & 0.97 & $\left(\mathrm{H}_{2} \mathrm{O}, \mathrm{CO}_{2}, \mathrm{O}_{3}\right)$ \\
16 & 13.3 & 0.56 & $\mathrm{CO}_{2}\left(\mathrm{H}_{2} \mathrm{O}, \mathrm{O}_{3}\right)$ \\
\hline
\end{tabular}

the AHI bands used in this study. Bands 9 and 10 are in the water vapor absorption band $(6.9$ and $7.4 \mu \mathrm{m})$, and they are sensitive to humidity in the upper and middle troposphere. The ozone absorption band (9.6 $\mu \mathrm{m})$ is sensitive to stratospheric ozone. AHI has only one $\mathrm{CO}_{2}$ absorption band $(13.3 \mu \mathrm{m})$, from which we can obtain information on $\mathrm{CTH}$. In the atmospheric window, we utilize four TIR bands centered at 8.6, $10.4,11.2$, and $12.4 \mu \mathrm{m}$. These four bands are sensitive to cloud properties such as CTH, COT, and CER. All the TIR bands have a spatial resolution of $2 \mathrm{~km}$ at the sub-satellite point (nadir).

The retrievals of cloud properties are formulated based on an optimal estimation (OE) approach (Rodgers 2000), which simultaneously fits the physics (forward) model to the measurements. The $\mathrm{OE}$ approach uses constraints from prior information and diagnoses rigorous uncertainties and retrieval quality. The OE approach has been widely applied in remote sensing of clouds in recent years (Cooper et al. 2006; Watts et al. 2011; Walther and Heidinger 2012; Poulsen et al. 2012; Sourdeval et al. 2013, 2015; Wang et al. 2016). In the forward model, the radiative transfer in the plane-parallel multilayered atmosphere is solved by the two-stream approximation, taking into account the effects of scattering and absorption in the atmosphere. Gaseous absorption is calculated by using the correlated $k$-distribution that is developed for the AHI by using an optimization technique (Sekiguchi and Nakajima 2008). Scattering properties of water droplets and ice particles are respectively obtained from the Lorenz-Mie theory and the database of Yang et al. (2013). In this paper, ice particles are assumed to have the shape of solid column aggregates with severely roughened particle surfaces as in the MODIS Collection 6 cloud product (Platnick et al. 2017). The ground surface temperature and emissivity are obtained from MODIS 8-day mean land and ocean products, whereas the atmospheric profiles, such as temperature, humidity, and ozone concentration, are interpolated spatially and temporally from the Modern-Era Retrospective Analysis for Research and Applications (MERRA) meteorological field product (Rienecker et al. 2011). In the cloud analysis, CTH (and cloud top pressure and temperature), COT, CER, and background surface temperature are estimated for the single-layered cloud case. Similar variables are retrieved in multilayer cloud case, but the cloud top pressure of the lower cloud layer is estimated instead of background surface temperature. A column is restricted to having no more than two well-separated cloud layers. Discrimination between a single- or two-layered cloud system is performed based on the retrieval cost, which is a measure of consistency between the model calculations and measurements. The cost greatly increases when multilayered clouds are present (e.g., Watts et al. 2011). Cloud thermodynamic phase (liquid water or ice) is also inferred (Iwabuchi et al. 2016).

\subsection{Assessment of model and measurement errors}

In using the present $\mathrm{OE}$ approach, it is important to create an appropriate assumption on the modeling and measurement errors. Firstly, the modeling and measurement errors are evaluated by comparing the brightness temperature from model calculations with that from daytime clear-sky observations over ocean. Full disk data from August 19 to 28, 2015 are used for this analysis. The clear-sky area is determined based on the MODIS Collection 6 cloud mask product (Ackerman et al. 1998; Baum et al. 2014), using collocated data with a time lag less than 5 minutes. If an area of about $(50 \mathrm{~km})^{2}$ in size is composed of only the "confidently clear" pixels in the cloud mask product, then the center area of about $(10 \mathrm{~km})^{2}$ is used for the measurement-model comparison. The measurement noise is estimated from the variance of measurementmodel differences within the $(10 \mathrm{~km})^{2}$ area because errors by uncertainties in sea surface temperature and atmospheric profile do not vary within such a small area as $(10 \mathrm{~km})^{2}$. The modeling errors arise primarily from the uncertainties in assumed temperature and humidity profiles. The mean values of measurementmodel differences within the $(10 \mathrm{~km})^{2}$ area are used to obtain global-mean error covariance matrix. The error covariance obtained in this way is used to estimate uncertainties in atmospheric profiles (temperature, humidity, and ozone concentration), assuming a sea surface temperature error as a standard deviation of 
$0.4 \mathrm{~K}$. Further description of the process for modeling atmospheric and surface uncertainties are presented in Iwabuchi et al. (2016).

Figure 1 shows the estimated error components due to atmospheric profile uncertainties for clear-sky and cloudy-sky conditions with different cloud top temperatures (CTTs). Errors in brightness temperatures are evaluated by Monte Carlo simulations where noise is added in forward model calculations based on the estimated atmospheric profile uncertainties. The errors for high CTT are close to that for clear-sky cases because the amounts of absorbing gases above a low-level cloud are almost the same as in clear-sky cases. The water vapor absorption bands (bands 9 and 10) tend to exhibit larger errors because uncertainties in temperature and water vapor amounts in the middle and upper troposphere increase model errors. However, the errors in the water vapor absorption bands significantly decrease as the CTTs decrease (i.e., higher $\mathrm{CTH}$ ) for two reasons: (1) the amount of water vapor tends to decrease with altitude, and (2) the peak in the weighting function for these bands peaks in the mid-to upper troposphere, and greatly decreases near the surface. Bands 11 and 13 in the atmospheric window exhibit the minimum error among the AHI TIR bands. The measurement noise is estimated to be $0.1-0.15 \mathrm{~K}$, as a standard deviation for all bands, which is small

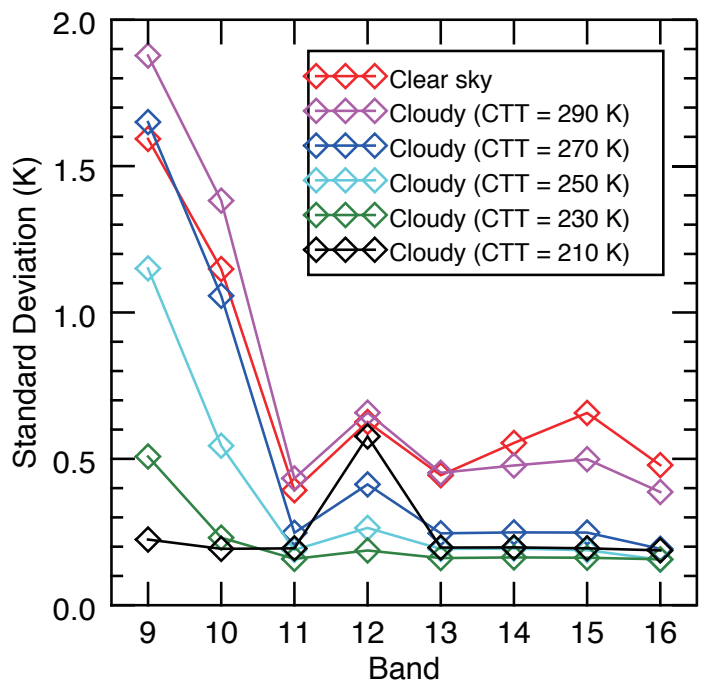

Fig. 1. Standard deviations of the measurementmodel error in brightness temperature for each AHI band owing to atmospheric profile errors. Errors are shown for clear-sky and cloudy-sky conditions assuming different cloud top temperatures.

compared to the errors due to atmospheric profile uncertainties.

Figure 2 shows the error correlation matrices whose elements are correlation coefficients between AHI bands. As expected, errors due to atmospheric profile are well correlated between bands, in which the two water vapor bands strongly correlate with each other. Strong correlations are also found among and between the atmospheric window and $\mathrm{CO}_{2}$ bands. The ozone band is relatively independent of the other bands, indicating that the ozone concentration error in the stratosphere is the major source of error in the band. When CTT is as low as $210 \mathrm{~K}$, all bands except the ozone band are strongly correlated because the water vapor above the cloud top equally affects those bands. These correlations are considered in the cloud property retrieval using the $\mathrm{OE}$ approach and they are important for producing retrievals with high accuracy. On the other hand, the estimated measurement noise is weakly correlated between bands.

(a) Clear sky

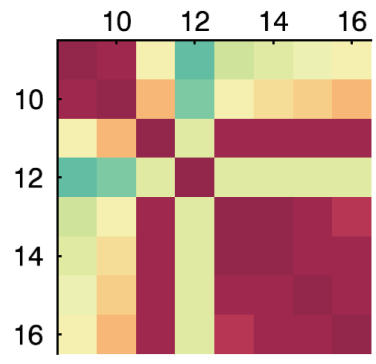

(c) $\mathrm{CTT}=250 \mathrm{~K}$
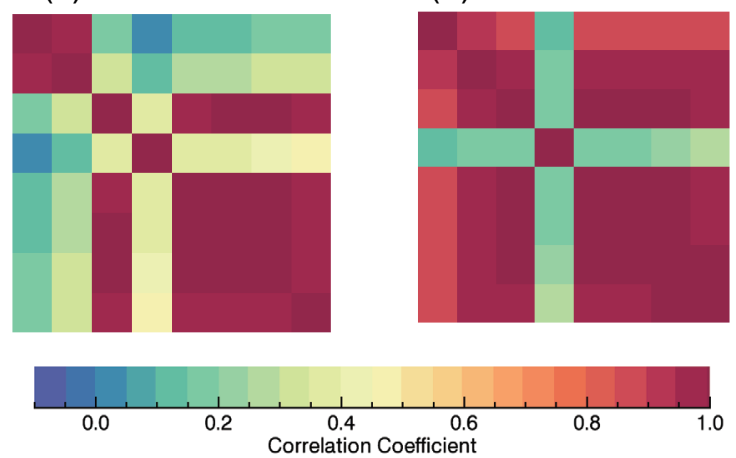

(b) CTT $=290 \mathrm{~K}$

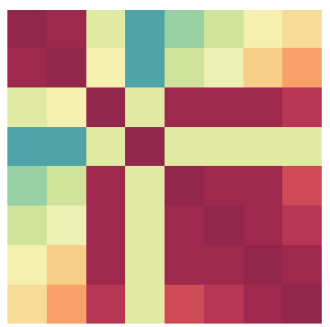

(d) CTT $=210 \mathrm{~K}$

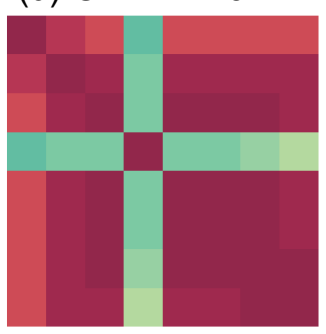

Fig. 2. The measurement-model error correlation matrices associated with atmospheric profile errors. The elements of the matrices are correlation coefficients between AHI bands. Vertical and horizontal axes correspond to the AHI band number. 


\subsection{Effectiveness of the single $\mathrm{CO}_{2}$ band}

The $\mathrm{CO}_{2}$ absorption bands at the wavelengths of 13-14 $\mu \mathrm{m}$ are useful for estimating CTH. A wellknown method for $\mathrm{CTH}$ retrieval is the $\mathrm{CO}_{2}$ slicing technique, which has been used in the MODIS product (Menzel et al. 2008). MODIS has four bands in the $\mathrm{CO}_{2}$ absorption spectrum, which offers a capability of using a combination of multiple $\mathrm{CO}_{2}$ bands with sensitivities on different levels of the atmosphere. However, AHI has only one $\mathrm{CO}_{2}$ absorption band at around $13.3 \mu \mathrm{m}$, which is similar to the ABI onboard the GOES-16. Heidinger et al. (2010) investigated the information content in the IR channels to estimate $\mathrm{CTP} / \mathrm{CTH}$ and showed quantitatively that the inclusion of even a single $\mathrm{CO}_{2}$ channel at around $13 \mu \mathrm{m}$ greatly reduces the solution space from that using only the IR window channels at 11 and $12 \mu \mathrm{m}$, leading to a more accurate retrieval.

In the following analysis, we further clarify the importance of including the single $\mathrm{AHI} \mathrm{CO}_{2}$ band for improving the estimation of CTP. The contribution of each AHI band to the CTP retrievals is investigated by retrieval simulations using noise-synthetic mea- surement simulations, in the same approach used in Iwabuchi et al. (2016). Measurement signals are simulated by the forward model calculations for perturbed atmospheric and surface states with random noise that obey the error covariance matrices estimated previously. Retrieval errors in CTP are evaluated by comparing the retrieved CTP with the initial values. For each state, a series of 1000 retrieval simulations are performed to evaluate the mean and standard deviation of retrieval error. Several assumptions are made in the simulations: an ice cloud with cloud geometrical thickness of $2 \mathrm{~km}$ and CER of $30 \mu \mathrm{m}$ is assumed in a typical tropical atmosphere over ocean. The satellite viewing zenith angle ranges from $0^{\circ}$ to $60^{\circ}$. Inaccuracies in the CTP retrievals will influence the COT and CER retrievals. Figure 3 shows the mean bias errors and standard deviations of CTP retrievals as functions of COT, for four configurations: 1) window bands only, 2) window and $\mathrm{CO}_{2}$ bands, 3) window and $\mathrm{H}_{2} \mathrm{O}$ bands, and 4) all bands. Without the use of absorption bands (i.e., using window bands only), the CTP retrieval error increases, particularly for optically thin clouds. Overestimation/underestimation of CTP
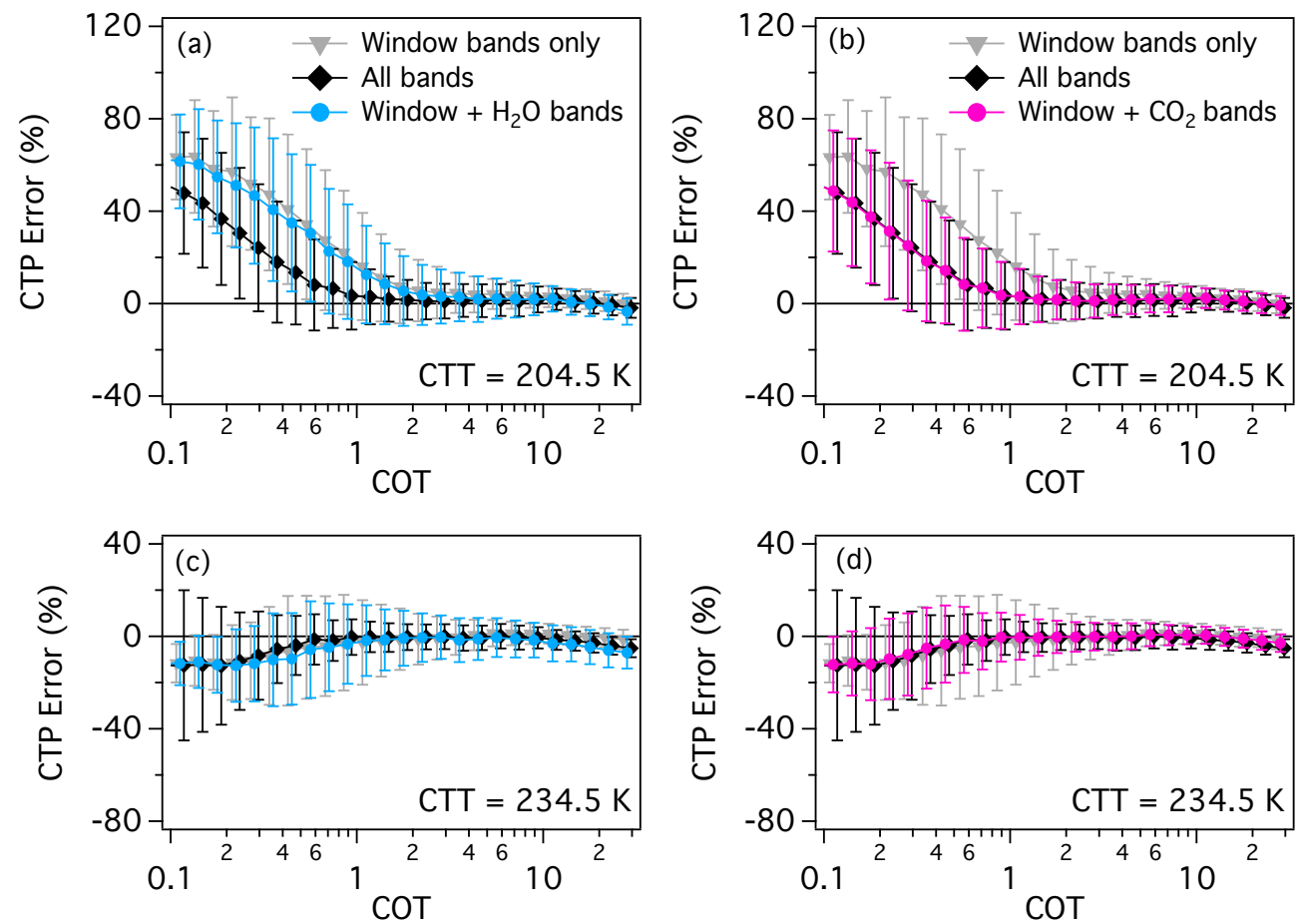

Fig. 3. Mean bias errors and standard deviation of error in CTP retrievals in cases of cloud top temperature (CTT) of $204.5 \mathrm{~K}(\mathrm{a}, \mathrm{b})$ and $234.5 \mathrm{~K}$ (c, d). Gray, black, pink and blue markers and lines correspond to the retrievals from TIR window bands only, all TIR bands, the window and $\mathrm{CO}_{2}$ absorption bands, and the window and $\mathrm{H}_{2} \mathrm{O}$ absorption bands, respectively. 
in optically thin cloud is caused by sensitivity lost and an assumption of a priori CTP that is in the middle of those corresponding to CTT of $204.5 \mathrm{~K}$ (Figs. 3a, b) and $234.5 \mathrm{~K}$ (Figs. 3c, d). Compared to the results of window bands only, the addition of the $\mathrm{CO}_{2}$ absorption band helps to improve the accuracy of CTP retrieval when COT is less than 5 . The retrievals by using the window and $\mathrm{CO}_{2}$ absorption bands achieve the same level of accuracy as those by using all TIR bands, implying that the $\mathrm{CO}_{2}$ absorption band has the largest contribution to the CTP retrievals. Additional analysis on the degree of freedom for signal (DOFS) shows that the DOFS increases by $0.3-0.4$ for optically thin clouds by adding the $\mathrm{CO}_{2}$ absorption band. The $\mathrm{H}_{2} \mathrm{O}$ absorption bands may be able to improve the accuracy of CTP retrievals (Figs. 3a, c) over that from window bands alone, but the beneficial contribution of these bands is often decimated by their large errors associated with the atmospheric profiles as previously shown in Fig. 1.

\section{Validation by comparison with active remote sensing}

\subsection{Validation methodology}

For validation, ICAS retrieval is compared with the raDAR/liDAR (DARDAR) cloud product (Delanoë and Hogan 2008, 2010). The DARDAR product used in this study is the DARDAR cloud product which provides vertical profiles of cloud mask and ice cloud properties including the ice water content, CER and extinction coefficient, which are inferred from combined Cloud-Aerosol Lidar and Infrared Pathfinder Satellite Observations (CALIPSO) lidar, CloudSat radar, and TIR measurements from CALIPSO radiometer and MODIS. DARDAR has a horizontal spatial resolution of $1.1 \mathrm{~km}$ and a vertical resolution of $60 \mathrm{~m}$. The data used for validation purpose cover a four days period from August 24 to 27, 2015, with the view zenith angles of AHI are limited to be less than $55^{\circ}$.

Temporal and spatial mismatches can arise uncertainties in the comparison between different cloud products. For our comparison, we involve only AHI full disk data whose observation time is the closest match to those of DARDAR data. The maximum time difference is $5 \mathrm{~min}$., within which a cloud can move by $6 \mathrm{~km}$ assuming a motion speed of $20 \mathrm{~m} \mathrm{~s}^{-1}$. In addition to the possible time lag, the collocation between AHI pixels and DARDAR profiles may be influenced by parallax issues because the AHI observes clouds over a variable range of viewing angles, while DARDAR contains cloud data from nadir-looking CloudSat radar profiles. To compare ICAS and DARDAR cloud estimates coherently, a parallax correction is applied to the locations of AHI pixels using the CTH estimates produced by ICAS. The parallax-corrected ICAS retrievals are interpolated to the longitudes and latitudes of the DARDAR profiles by employing a nearest-neighbor approach. It should be noted that the collocation between ICAS retrievals and DARDAR profiles may contain some uncertainties owing to the uncertainty in the $\mathrm{CTH}$ estimates. For example, if the $\mathrm{CTH}$ estimate has an error of $3 \mathrm{~km}$, the horizontal location error can be $3 \mathrm{~km}$ when the view zenith angle is $45^{\circ}$. Even with these caveats, the comparison between the ICAS results and the DARDAR cloud retrievals is still valuable for gaining some insights on the strengths and weaknesses of the $\mathrm{OE}$ approach, as will be shown in the following section.

\subsection{Comparison of CTH}

Figure 4 shows the DARDAR cloud mask overlaid with the ICAS CTH retrievals for a scene over Borneo Island and South China Sea on August 27, 2015. ICAS CTH is shown with different markers depending on the cloud phase (ice or water) and whether the solution is optimal. CTHs in optimal solutions (blue triangle for ice and green circle for water) generally agree well with the DARDAR CTH. However, ICAS overestimates the $\mathrm{CTH}$ of middle clouds around regions $\mathrm{A}$ and $\mathrm{D}$ by $1-4 \mathrm{~km}$. The very high $(\mathrm{CTH} \sim 15-16 \mathrm{~km})$, geometrically thin clouds between $\mathrm{B}$ and $\mathrm{C}$ are also optically thin, and are below the threshold for detectability. If such an optically thin cloud overlies a lower cloud, the ICAS CTH is located between the upper and lower clouds as shown around B and E. These results are consistent with previous studies involving limits for optically thin ice cloud and multilayer cloud detection (e.g., Baum and Wielicki 1994; Holz et al. 2008; Menzel et al. 2008; Watts et al. 2011).

Figure 5 shows the CTH comparison for clouds that have ice particles occupying the cloud top in DARDAR profile. Single-layer and multilayer clouds are identified with DARDAR data as the baseline, and these clouds are analyzed separately. If the comparison is limited to single-layer clouds in DARDAR (Fig. 5a), a good agreement is shown between the CTH of ICAS and DARDAR with a correlation coefficient of 0.875 , mean bias error (MBE) of $-1.0 \mathrm{~km}$, and root mean square error (RMSE) of $2.1 \mathrm{~km}$. For multilayer clouds (Fig. 5b), ICAS CTH for ice cloud is significantly underestimated compared to the DARDAR CTH of the uppermost cloud, with a correlation coefficient of $0.521, \mathrm{MBE}$ of $-3.1 \mathrm{~km}$, and RMSE of 4.4 $\mathrm{km}$. Histograms of ICAS-DARDAR CTH difference 


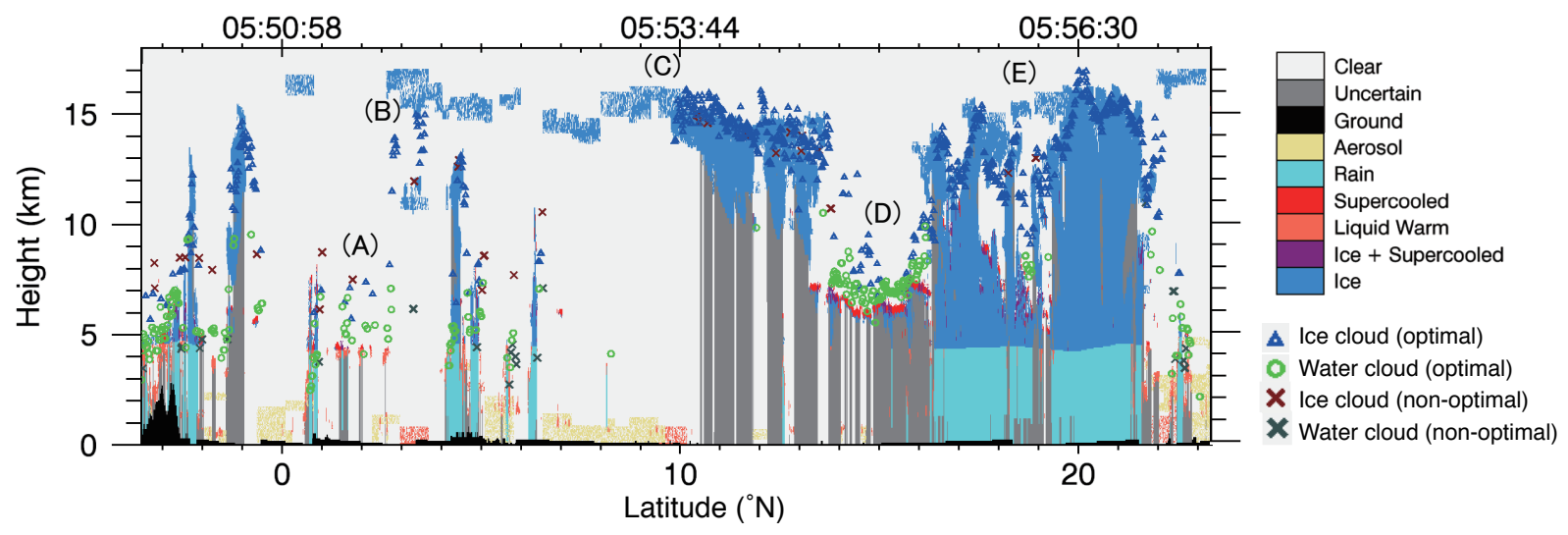

Fig. 4. DARDAR simplified cloud mask categorization and ICAS CTH retrievals for a scene over Borneo Island and the South China Sea on Aug. 27, 2015. DARDAR mask is denoted by color shades, and ICAS CTH is shown with different markers for ice and water cloud and optimal and non-optimal solutions. The "uncertain" flag in DARDAR profiles are caused by the inability to perform DARDAR mask retrieval, which usually occurs in the regions with complete attenuation of lidar signal. See text for explanations of markers A to E.

(a) Single-layer, ice

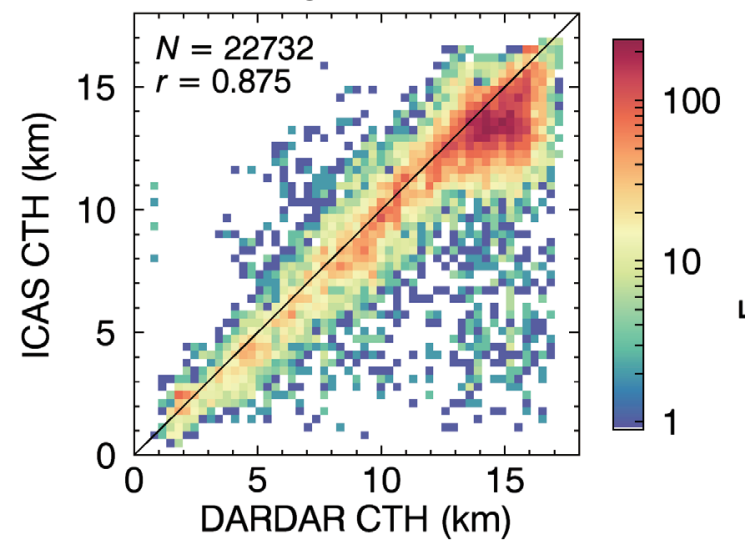

(b) Multilayer, ice

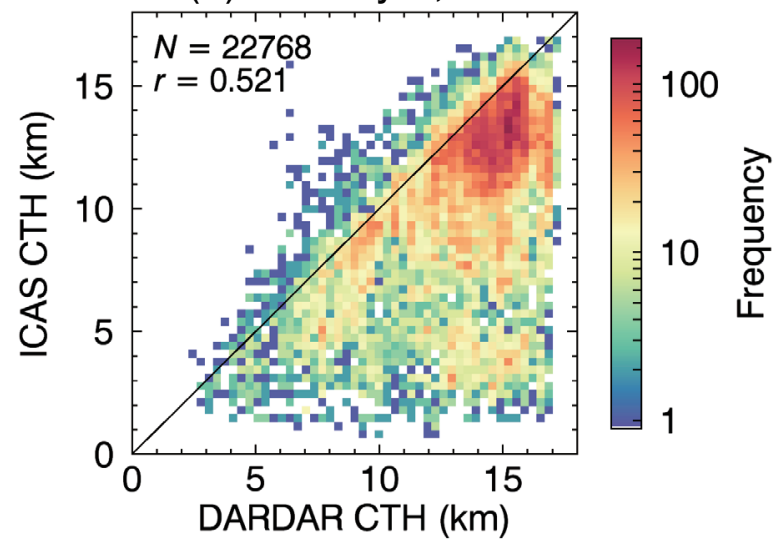

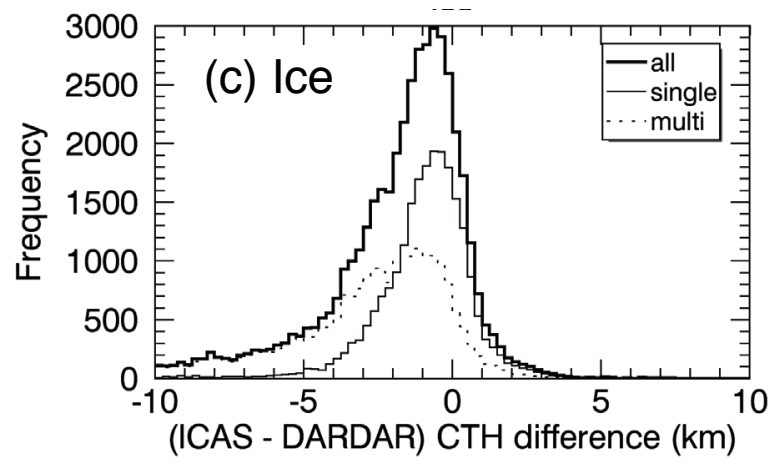

Fig. 5. Joint histograms of DARDAR and ICAS CTH estimates for (a) single-layer cloud system and (b) multilayered cloud system, for cases with cloud ice at the cloud top in DARDAR profile. In multilayered cloud cases, the CTH of uppermost cloud is compared. (c) Histogram of ICAS-DARDAR CTH differences. Singlelayered and multilayered cloud systems are identified by DARDAR. 
in Fig. 5c show that underestimation of ICAS CTH in multilayer cloud cases is the primary contributor to the total deficiency of CTH estimation for ice clouds using ICAS. Similar issue was found in TIR-based cloud top retrieval by Holz et al. (2008). They showed that the cloud top inferred from the $\mathrm{CO}_{2}$ slicing technique is significantly lower than the upper cloud top in the multilayer cloud cases. As shown in Fig. 4, the weak sensitivity of TIR measurement to high, thin cloud is a major source of error in cloud retrieval by ICAS. Although the current operational satellite cloud retrieval systems generally assume that the observed cloud has a single layer, it is very likely that the detection, if not analysis, of multilayered cloud systems will become a component of operational retrievals in the future.

Figure 6 shows the CTH comparison for clouds that have liquid water occupying the cloud top in DARDAR profile. The correlation coefficient is 0.706 with MBE of $0.5 \mathrm{~km}$ for ICAS and RMSE of $1.8 \mathrm{~km}$. As the MBE suggests, there is a tendency
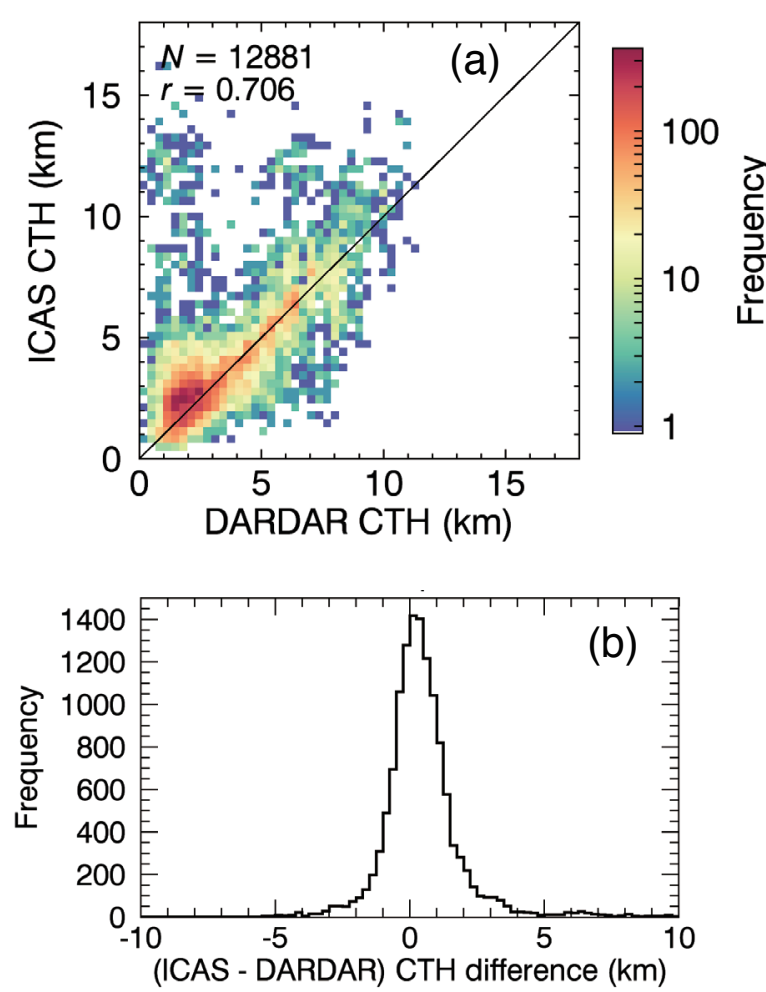

Fig. 6. Similar to Fig. 5, but for comparison of water clouds with liquid water at the cloud top in DARDAR profile, in which (a) the joint histogram and (b) the histogram of CTH difference. for ICAS to overestimate the $\mathrm{CTH}$ of water clouds. This overestimation can be ascribed to temperature inversion near the cloud top, as shown in Baum et al. (2012) for MODIS Collection 5 cloud products. Here temperature profiles taken from the DARDAR product are used to build composite profiles for different ranges of ICAS-DARDAR differences in CTH and the results are shown in Fig. 7. When ICAS CTH agrees well with DARDAR (Fig. 7a), temperature depression rate is usually about $6.5 \mathrm{~K} \mathrm{~km}^{-1}$ around the cloud top. When ICAS largely overestimates the CTH (Fig. 7b), temperature profile tends to show smaller (or possibly negative) depression rate within $\pm 0.5 \mathrm{~km}$ from the cloud top. However, it should be noted that the DARDAR temperature profile data are originally from coarse resolution data of the European Centre for Medium-Range Weather Forecasts (ECMWF) model analysis. The actual temperature inversion near the cloud top can be more pronounced than that has been shown here. In addition to the reduction of measurement and modeling errors, atmospheric profile data with high vertical resolution are needed to increase the accuracy of CTH estimates. Moreover, the investigation on the climatology of temperature profile near the cloud top as a function of cloud properties (e.g., COT and $\mathrm{CTH}$ ), including geographical distribution, diurnal cycle, and seasonal variation of these properties, may provide useful constraints for a better $\mathrm{CTH}$ estimation.

\subsection{Comparison of COT and CER}

Figure 8 shows a comparison of COT for singlelayered ice clouds identified in both ICAS and DARDAR products. Although the COT generally agrees well for moderate COTs around 1-5, ICAS significantly underestimates COTs when DARDAR COT is larger than 6-8 approximately, which may be attributed to the insensitivity of TIR measurements to large COT. Although it is possible for ICAS to detect a high, thick cloud with COT more than 8 , a quantitative COT retrieval for such cloud is extremely difficult. Figure 8 also shows that when ICAS COT is less than 1, DARDAR COT tend to be a few times larger than ICAS COT. The exact reason for this discrepancy is not fully understood. It is possible that DARDAR COT has a positive bias, particularly for optically thin clouds (COT $\leq 1)$, owing to the large extinction-to-backscattering ratio in DARDAR algorithm as suggested by Saito et al. (2017). Some errors may also be present in ICAS COT since ICAS assumes vertically homogeneous clouds, while in fact, optically thin cloud may have large geometrical thickness and vertical inhomogeneity. Holz et al. (2008) 

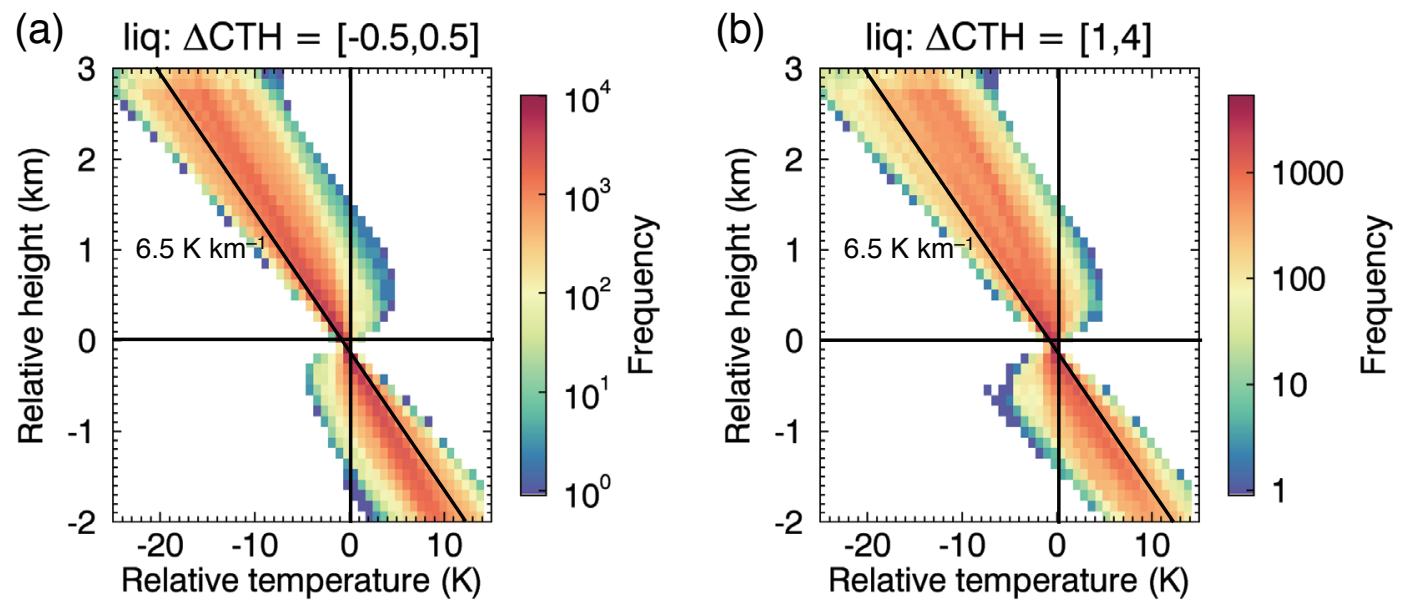

Fig. 7. Joint histograms of composite temperature profile for water cloud in DARDAR product, for different ranges of ICAS-DARDAR difference (DCTH) in CTH. The relative height and temperature are calculated from values at the cloud top found in DARDAR profile. The temperature data in the DARDAR product comes originally from spatiotemporal interpolation of the ECMWF modeled fields.

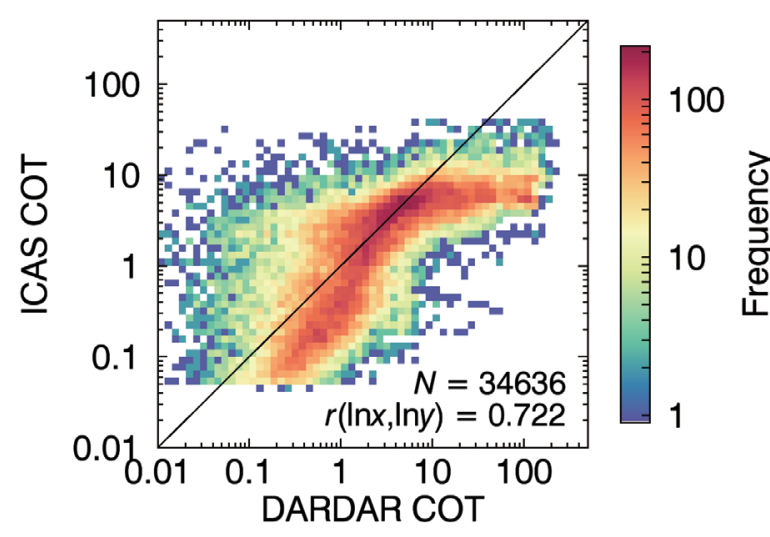

Fig. 8. Joint histogram of ICAS and DARDAR COT estimates for single-layered ice clouds, using cloud pixels that exhibit ice phase in the entire DARDAR profile.

showed that MODIS sees into the cloud to an optical thickness of approximately 1 , hence for a geometrically thick cloud, the CTH retrieved from passive sensor measurements may be quite different than that inferred from DARDAR.

In general, CloudSat and CALIPSO products indicate that cloud ice water content (IWC) and CER exhibit vertical inhomogeneity (Ham et al. 2013). DARDAR provides the vertical profile of CER. To compare ICAS CER retrieval with DARDAR, column-mean CER is derived from DARDAR profiles for an ice cloud layer. Only single-layered ice cloud is considered here. The column-mean CER is defined as

$$
R_{e}=\frac{3 \int_{z_{b}}^{z_{t}} V(z) d z}{4 \int_{z_{b}}^{z_{t}} A(z) d z},
$$

where $V$ and $A$ are particle volume and projection area densities, respectively; $z$ is the altitude; and $z_{t}$ and $z_{b}$ are altitudes at the cloud top and base, respectively. Thus, $R_{e}$ is proportional to a ratio of column-integrated cloud particle volume to column-integrated cloud particle projected area. The above definition of $R_{e}$ is similar to $r_{e}(z)$, which is the local CER at altitude $z$ defined as

$$
r_{e}(z)=\frac{3 V(z)}{4 A(z)}
$$

The above definition in Eq. (1) is equivalent to the column-mean CER averaged by an extinction coefficient weighting (McFaqurhar and Heymsfield 1998), assuming the extinction efficiency factor to be 2 . The $\operatorname{IWC} w(z)$ is related to the $V(z)$ by

$$
w(z)=\rho_{b} V(z),
$$

where $\rho_{b}$ is the bulk density of water ice. With Eqs. (2) and (3), Eq. (1) can be transformed into 


$$
R_{e}=\frac{\int_{z_{b}}^{z_{t}} w(z) d z}{\int_{z_{b}}^{z_{t}} w(z) / r_{e}(z) d z},
$$

which can be calculated using $w$ and $r_{e}$ values available from DARDAR. We note that the TIR measurement is sensitive primarily to the upper part of the cloud (Zhang et al. 2010). The sensitivity decreases with decreasing transmittance from the cloud top, depending on several factors including wavelength and satellite viewing angle. The sensitivity is approximated as $\exp (-\tau)$, where $\tau$ is COT from the cloud top. Thus, a sensitivity-weighted column-mean CER here is defined as

$$
R_{e}^{\prime}=\frac{\int_{z_{b}}^{z_{t}} w(z) \exp [-\tau(z)] d z}{\int_{z_{b}}^{z_{t}} w(z) / r_{e}(z) \cdot \exp [-\tau(z)] d z},
$$

which indicates greater sensitivity to the upper part of the cloud.

Figure 9 shows the CER comparison of ICAS and DARDAR based on Eq. (5). Since ICAS CER can be retrieved accurately when COT is less than 6 (Iwabuchi et al. 2016), the comparison is made only for pixels with COT between 0.1 and 6 . Nevertheless, ICAS CER does not agree well with DARDAR column-mean CER, with a correlation coefficient of 0.35 and MBE of $-7.2 \mu \mathrm{m}$. Better agreement is shown for the sensitivity-weighted column-mean $\left(R_{e}^{\prime}\right)$ with MBE of $-4.7 \mu \mathrm{m}$ although the correlation shows no improvement. DARDAR CERs range from 25 to 50 $\mu \mathrm{m}$ and exhibits small variability compared to ICAS CER. ICAS shows a significant occurrence of CER less than $20 \mu \mathrm{m}$, while DARDAR shows no presence of such small CER. Further study is needed to interpret the differences in CER. In thick ice clouds, CER and IWC tend to increase with increasing distance from the cloud top. In such cases, spectral features in the TIR measurements, from which CER is inferred, could differ from that of a homogeneous cloud. These results stress the necessity of more detailed investigation on the effects of cloud vertical inhomogeneity to the CER retrieval.

\section{A case study of diurnal cycle of cloud system}

As an application, the ICAS retrievals are used to investigate the diurnal cycle of clouds in a tropical region using the Himawari-8 data with 10-minute temporal resolution. The analysis period is eight days from 12-19 January 2016. The region is from $120^{\circ}$
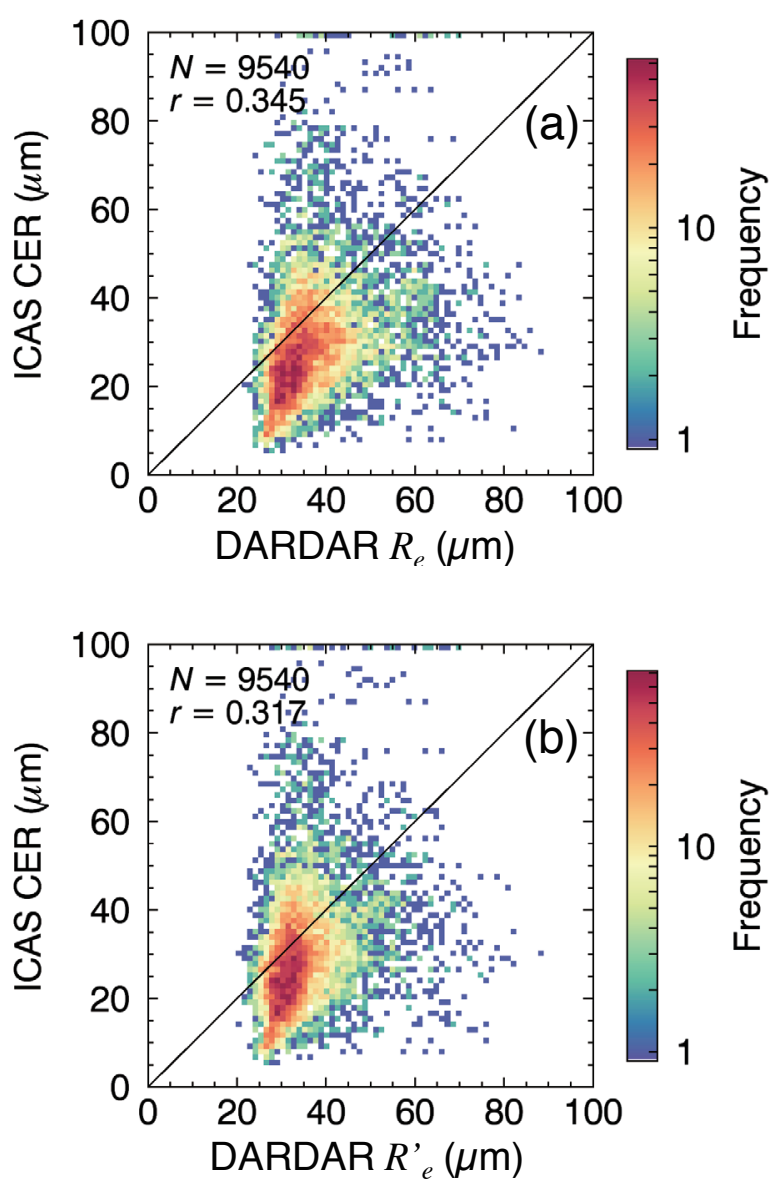

Fig. 9. Joint histograms of ICAS CER estimate and DARDAR (a) column-mean CER and (b) sensitivity-weighted column-mean CER (see text for definitions), for single-layered ice clouds with ice phase in the entire DARDAR profile. Results are shown for COT in the range of 0.1-6.

to $160^{\circ} \mathrm{E}$ longitude and from $10^{\circ} \mathrm{S}$ to $2^{\circ} \mathrm{N}$ latitude. The region covers the New Guinea Island and its surrounding oceanic areas. In general, convective activity strengthens in the afternoon over land and early morning over ocean by various mechanisms including land-sea breezes, propagation of gravity waves forced by convection in remote areas, and direct radiationconvection effect (Chen and Houze 1997; Yang and Slingo 2001; Mapes et al. 2003a, b).

Figure 10 shows the time series of COT and $\mathrm{CTH}$ retrieved by ICAS. The results are shown every 3 hours from $0000 \mathrm{LST}$ based on the $135^{\circ} \mathrm{E}$ longitude. High clouds predominantly cover the area throughout the day. The coverage of high clouds is the highest at night over land, while around noon, the coverage of 
LST

(@135

0

3

6

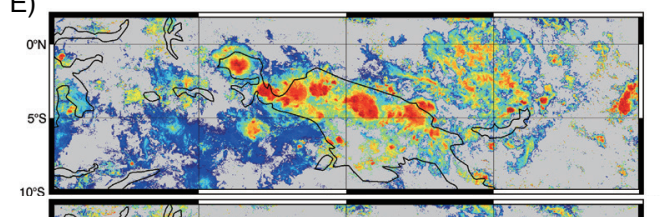

9

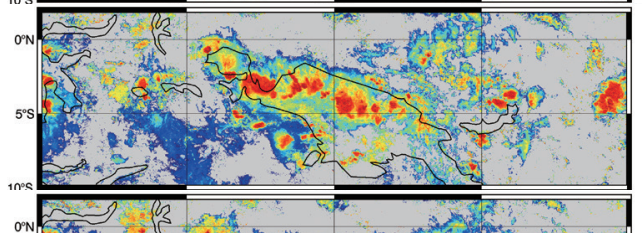

12

15

8

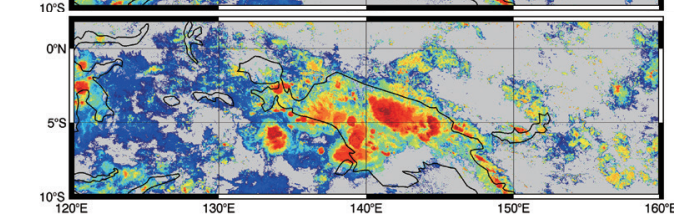

(a) COT
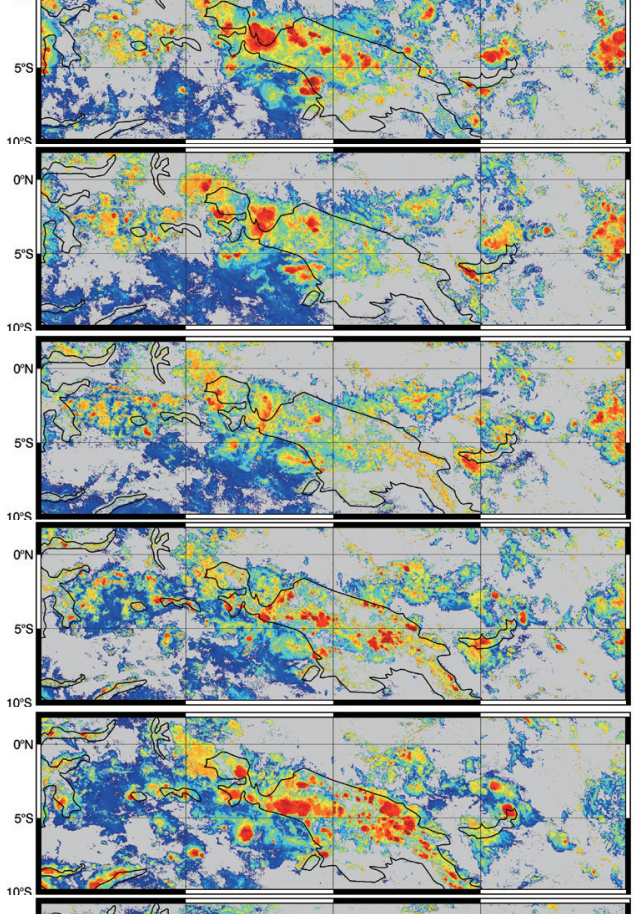

21

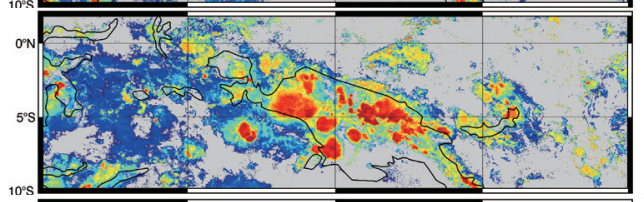

(b) $\mathrm{CTH}$
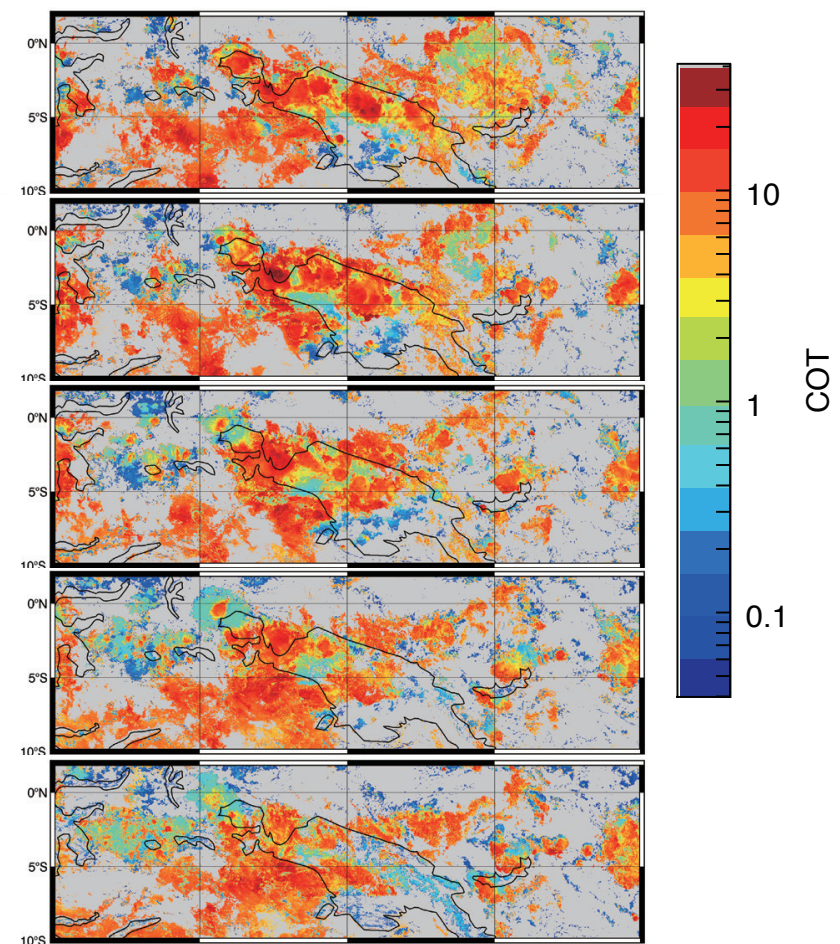

Fig. 10. Time series of COT and CTH estimated by ICAS for the New Guinea region. Results are shown every 3 hours from 1500 UTC on January 14, 2016. The local time is calculated at $135^{\circ} \mathrm{E}$ longitude.

high clouds decreases over land and mid-level clouds appear. Note that the lower cloud layers are not shown in the present results when high clouds are overlying the lower clouds. This inability in showing the prop- erties of lower cloud layers is one of the limitations of passive remote sensing. The growth of relatively small-scale convective clouds occurs from 1500 to 1800 LST. Afterwards, the cells increase in size and 
become organized to form larger scale systems. Several mesoscale convective systems with circular shape and size of about $100-200 \mathrm{~km}$ are finally formed at 2100 LST. From 0000 to 0900 LST, large convective clouds with spreading cirrus anvils in their peripheries are seen over land.

The diurnal characteristics of the above cloud systems can be assessed quantitatively by calculating the cloud fraction of different cloud types, as shown in Figs. 11a, 11c, and 11e. Here, the CTP values at 680 and $440 \mathrm{hPa}$ are used as the boundaries for separating the clouds into low, middle and high cloud types. In addition, the high clouds are further separated into cirrus, cirrostratus, and opaque high clouds (OHCs) according to their COT, by using COT boundaries at 1 and 6. Cloud fractions are calculated separately for data over land, coasts and ocean. The coastal region is defined as the water within $100 \mathrm{~km}$ from the coastline, while the ocean is over $100 \mathrm{~km}$ from the coastline. The cloud fractions are calculated every 10 minutes in LST, averaged over the eight day period. The temporal variation for each cloud type is smoothed using a moving average approach with a full width window of 50 minutes.
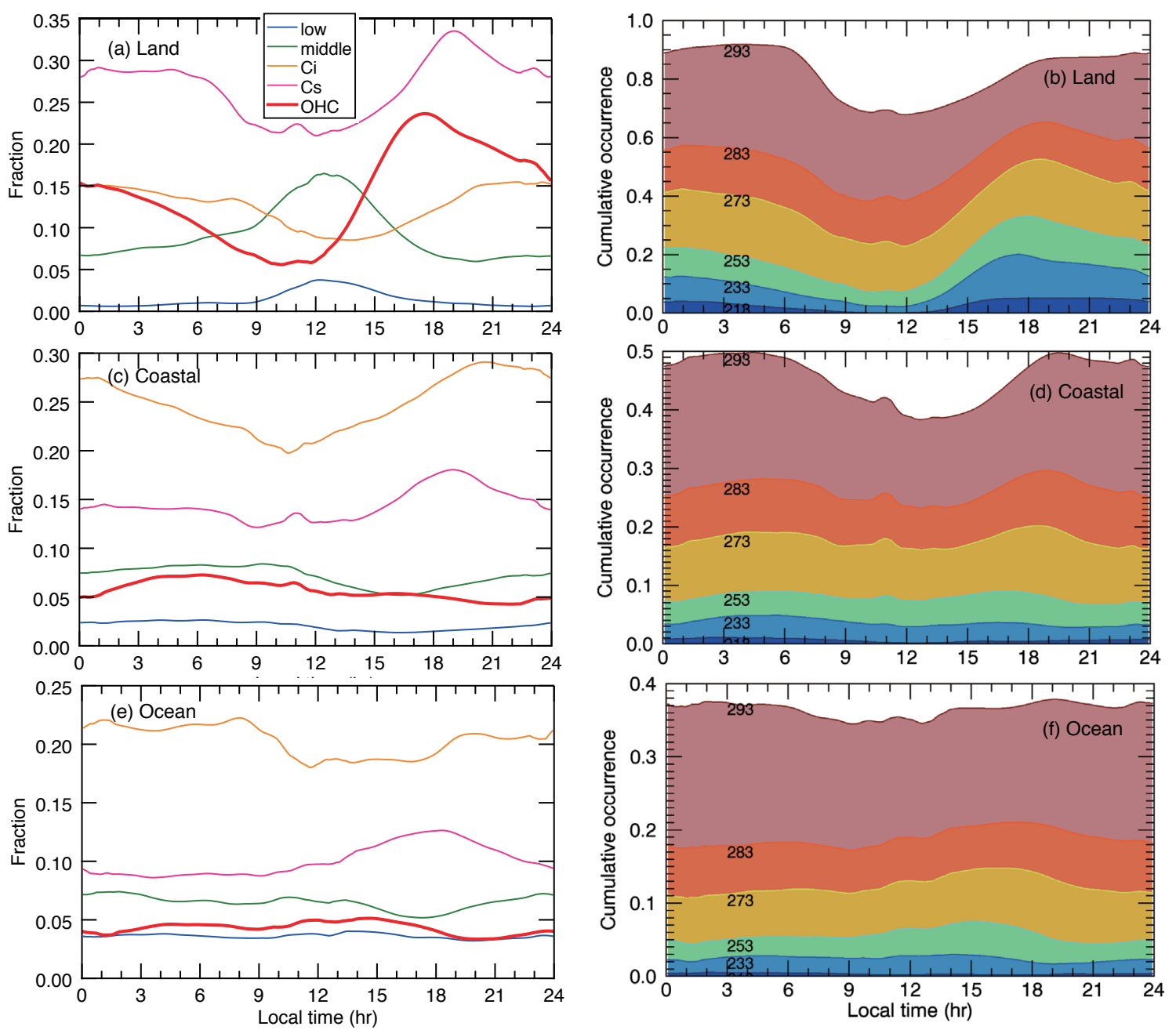

Fig. 11. Temporal variation of (a, c, e) cloud fractions for low and middle clouds, cirrus (Ci), cirrostratus (Cs), and opaque high cloud $(\mathrm{OHC})$; and $(\mathrm{b}, \mathrm{d}, \mathrm{f})$ brightness temperature at AHI band $13(10.5 \mu \mathrm{m})$ over $(\mathrm{a}, \mathrm{b})$ land, (c, d) coast and (e, f) ocean. The temporal variation is calculated for eight days of January 12-19, 2016 over the region shown in Fig. 10. For the brightness temperature, the cumulative distribution function is calculated at every 10 minutes, with the occurrence fractions of the brightness temperature below $213,233,253,273$, and $293 \mathrm{~K}$ are shown on the vertical axis. 
Over land, the amount of OHCs is the smallest around 1000-1200 LST (Fig. 11a). Low and middle clouds over land exhibit the maximum peaks at around 1200 LST. Subsequently, the fraction of middle clouds experiences a sharp decrease, while the amount of OHCs increases rapidly from 1200 to 1700 LST. The amount of the OHCs decreases slowly from 1800 to 0900 LST. The cirrostratus clouds show a maximum at 1900 LST, which corresponds to about 2 hours after the maximum of the OHCs. The cirrostratus clouds are likely associated with the peripheries of deep convective cloud, when the anvil grows over time. Previous studies have shown that the presence of spreading cirrus clouds generated from deep convection is the characteristic in mature and dissipation stages of deep convective system. The area covered by cirrus grows in the mature stage of deep convective system, for 1-2 hours after the surface convective rainfall began to weaken. The diurnal cycle of the cirrus cloud fraction is similar in shape to those of cirrostratus clouds, but there is a time lag of $2-3$ hours. Over coasts, cirrostratus and cirrus clouds are spreading at around 1900 and 2100 LSTs, respectively (Fig. 11c), and it seems that these clouds are mostly associated with the deep convective clouds formed over land. The diurnal cycle of the $\mathrm{OHC}$ is less pronounced over coasts than over land. Although the areal fraction of $\mathrm{OHC}$ is generally small (less than $7 \%$ ), a wide peak is seen from 0300 to 0800 LST. Over ocean, the diurnal cycles of every cloud type seem to be less pronounced than those over land. Coverage of cirrostratus clouds shows a maximum at about 1900 LST. These results seem to exhibit the typical diurnal cycle of the cloud system in this region, despite the short analysis period of only eight days.

Previous studies have examined the temporal evolution of the convective cloud from the change in the brightness temperature in the $11-\mu \mathrm{m}$ band or the occurrence frequency of pixels whose brightness temperature is lower than a threshold (Chen and Houze 1997; Yang and Slingo 2001). Similarly, we examine the brightness temperature at the AHI band 13 (10.5 $\mu \mathrm{m})$ over the study area for the eight days from January 12 to 19,2016 . Figures $11 \mathrm{~b}, 11 \mathrm{~d}$, and $11 \mathrm{f}$ show the cumulative distribution functions of the brightness temperature every 10 minutes for land, coasts, and ocean, respectively. The occurrence fractions of the brightness temperature below 213, 233, 253, 273, and $293 \mathrm{~K}$ are shown on the vertical axis. Very low brightness temperature is considered to be associated with an opaque cold cloud. Indeed, the variation in the cloud amount of OHC (Figs. 11a, c, e) is very similar to the change in the occurrence of brightness temperature less than $233 \mathrm{~K}$. However, when the brightness temperature is moderately low, a variety of cloud types may be present. For example, the occurrence of brightness temperature in the range of $233-253$ or 253-273 K does not correspond to a variation of any particular cloud type. As shown by Inoue et al. (2006), the use of higher threshold for TIR window measurement results in the inclusion of optically thicker cirrus cloud rather than cumulonimbus cloud. Analysis using only the variations in brightness temperature may not be sufficient to capture the temporal variation of a cloud type other than deep convective cloud (OHCs). By using the retrieved properties of the clouds, an accurate identification of various cloud types is possible, thus the temporal evolution of these clouds can be investigated more thoroughly.

\section{Conclusions}

The method to estimate macroscopic, microphysical and optical properties of clouds from infrared measurement data was applied to the measurements from AHI onboard the Himawari-8 satellite. The high spatial resolution and multichannel measurements by Himawari- 8 are used to estimate various cloud properties with high accuracy using our OE algorithm known as the ICAS. For application to AHI, the measurement-model error covariance matrix used in the inversion algorithm is computed based on the comparison of clear-sky data over ocean between observation data and model calculations. From a sensitivity test, we demonstrated that the $\mathrm{CTH}$ can be estimated accurately by using the $13.3-\mu \mathrm{m} \mathrm{CO}_{2}$ band available in the AHI. The retrieved CTH, COT, and CER were verified by comparison with active remote sensing products from DARDAR. The cloud properties are fairly accurate in single-layer cloud cases. In multilayer cloud cases when an optically thin high-level cloud overlies a lower cloud layer, the estimated CTH is located between the heights of the two cloud layers, depending on the optical thickness of the uppermost layer. The presence of multilayered clouds can result in large CTH errors. Future improvement on the analysis of multilayer clouds is a high priority task. CTH estimation for lower-level clouds, particularly in marine environments where stratocumulus dominates, is also uncertain when there is a temperature inversion layer near the cloud top. Since the current algorithm assumes a homogeneous cloud, sensitivity is low when the cloud is optically thick (COT $>5)$; the COT may be underestimated for high COT. Estimation of the cloud properties including CTH, COT and CER is 
biased when vertical inhomogeneity is present in the cloud layer. Improvement of CER retrieval accuracy is expected by incorporating vertical inhomogeneity into the cloud model used in the inversion process. As shown in this study, there are multiple possible methods to compare cloud-column-mean CER based on active sensor measurements (such as DARDAR) with or without considering the sensitivity of infrared measurements. There is no consensus yet in the community on the best method for comparison with active remote sensing, making the comparison should be addressed with more attention in the future. Comparison between different cloud products should be done continuously as it holds a great importance for understanding the advantages and limitations of each product.

As an application example, we analyzed data for eight full days from January 12 to 19, 2016 to investigate the diurnal cycle of the cloud system over the New Guinea region. Our cloud analysis permits the study on the cloud evolution of multiple cloud types. Over land, high clouds are at a minimum around noon, middle clouds increase from 900 to 1200 LST, and deep convective clouds develop rapidly in the afternoon (during 1200-1700 LST), with a subsequent increase in upper clouds such as cirrus clouds. Over the coastal areas, the peak of cirrostratus and cirrus clouds from the land-originated deep convection appears to spread in the late afternoon (1800-2400 LST), and a broad peak of convective cloud fraction is seen in the early morning. These features are consistent with typical diurnal cycle of cloud systems in a tropical area. The present study demonstrates the feasibility of using Himawari- 8 for studies on the cloud system evolution with high temporal resolution. Achieving an advanced understanding on the physics and dynamics of the diurnal and life cycles of the cloud-precipitation systems will be more convenient on account of the measurement data by Himawari-8, which is available every 10 minutes for the full disk area.

\section{Acknowledgments}

The authors are grateful to Shogo Sakai of the Graduate School of Science, Tohoku University for helping the data analysis in Section 4. This work was conducted as a part of the 1st Research Announcement on the Earth Observations of the Japan Aerospace Exploration Agency (JAXA) (PI No.: RA1R306). The Himawari- 8 data used in the present study was obtained from the NICT Science Cloud at National Institute of Information and Communications Technology (NICT), Japan. Ping Yang acknowledges support by the endowment funds related to the David Bullock Harris Chair in Geosciences at the College of Geosciences, Texas A\&M University. Bryan Baum acknowledges the support of NASA grant NNX14AP 65A.

\section{References}

Ackerman, S. A., K. I. Strabala, W. P. Menzel, R. A. Frey, C. C. Moeller, and L. E. Gumley, 1998: Discriminating clear sky from clouds with MODIS. J. Geophys. Res., 103, 32141-32157.

Baum, B. A., and B. A. Wielicki, 1994: Cirrus cloud retrieval using infrared sounding data: Multilevel cloud errors. J. Appl. Meteor., 33, 107-117.

Baum, B. A., W. P. Menzel, R. A. Frey, D. Tobin, R. E. Holz, S. A. Ackerman, A. K. Heidinger, and P. Yang, 2012: MODIS cloud top property refinements for Collection 6. J. Appl. Meteor. Climatol., 51, 1145-1163.

Baum, B. A., P. Yang, A. J. Heymsfield, A. Bansemer, B. H. Cole, A. Merrelli, C. Schmitt, and C. Wang, 2014: Ice cloud single-scattering property models with the full phase matrix at wavelengths from 0.2 to $100 \mu \mathrm{m}$. $J$. Quant. Spectrosc. Radiant. Transfer, 146, 123-139.

Bessho, K., K. Date, M. Hayashi, A. Ikeda, T. Imai, H. Inoue, Y. Kumagai, T. Miyakawa, H. Murata, T. Ohno, A. Okuyama, R. Oyama, Y. Sasaki, Y. Shimazu, K. Shimoji, Y. Sumida, M. Suzuki, H. Taniguchi, H. Tsuchiyama, D. Uesawa, H. Yokota, and R. Yoshida, 2016: An introduction to Himawari-8/9 - Japan's new-generation geostationary meteorological satellites. J. Meteor. Soc. Japan, 94, 151-183.

Chen, S. S., and R. A. Houze, Jr., 1997: Diurnal variation and life-cycle of deep convective systems over the tropical Pacific warm pool. Quart. J. Roy. Meteor. Soc., 123, 357-388.

Cooper, S. J., T. S. L'Ecuyer, P. Gabriel, A. J. Baran, and G. L. Stephens, 2006: Objective assessment of the information content of visible and infrared radiance measurements for cloud microphysical property retrievals over the global oceans. Part II: Ice clouds. $J$. Appl. Meteor. Climatol., 45, 42-62.

Delanoë, J., and R. J. Hogan, 2008: A variational scheme for retrieving ice cloud properties from combined radar, lidar, and infrared radiometer. J. Geophys. Res., 113, D07204, doi:10.1029/2007JD009000.

Delanoë, J., and R. J. Hogan, 2010: Combined CloudSatCALIPSO-MODIS retrievals of the properties of ice clouds. J. Geophys. Res., 115, D00H29, doi:10.1029/ 2009JD012346.

Ham, S.-H., B.-J. Sohn, S. Kato, and M. Satoh, 2013: Vertical structure of ice cloud layers from CloudSat and CALIPSO measurements and comparison to NICAM simulations. J. Geophys. Res., 118, 9930-9947.

Heidinger, A. K., M. J. Pavolonis, R. E. Holz, B. A. Baum, and S. Berthier, 2010: Using CALIPSO to explore the 
sensitivity to cirrus height in the infrared observations from NPOESS/VIIRS and GOES-R/ABI. J. Geophys. Res., 115, D00H20, doi:10.1029/2009JD012152.

Holz, R. E., S. A. Ackerman, F. W. Nagle, R. Frey, S. Dutcher, R. E. Kuehn, M. A. Vaughan, and B. Baum, 2008: Global Moderate Resolution Imaging Spectroradiometer (MODIS) cloud detection and height evaluation using CALIOP. J. Geophys. Res., 113, D00A19, doi: 10.1029/2008JD009837.

Inoue, T., H. Ueda, and T. Inoue, 2006: Cloud properties over the Bay of Bengal derived from NOAA-9 split window data and TRMM PR product. SOLA, 2, 4144.

Iwabuchi, H., M. Saito, Y. Tokoro, N. S. Putri, and M. Sekiguchi, 2016: Retrieval of radiative and microphysical properties of cloud from multispectral infrared measurements. Progr. Earth Planet. Sci., 3, 32, doi: 10.1186/s40645-016-0108-3.

Mapes, B. E., T. T. Warner, M. Xu, and A. J. Negri, 2003a: Diurnal patterns of rainfall in northwestern South America. Part I: Observations and context. Mon. Wea. Rev., 131, 799-812.

Mapes, B. E., T. T. Warner, and M. Xu, 2003b: Diurnal patterns of rainfall in northwestern South America. Part III: Diurnal gravity waves and nocturnal convection offshore. Mon. Wea. Rev., 131, 830-844.

McFarquhar, G. M., and A. J. Heymsfield, 1998: The definition and significance of an effective radius for ice clouds. J. Atmos. Sci., 55, 2039-2052.

Menzel, W. P., R. A. Frey, H. Zhang, D. P. Wylie, C. C. Moeller, R. E. Holz, B. Maddux, B. A. Baum, K. I. Strabala, and L. E. Gumley, 2008: MODIS global cloud-top pressure and amount estimation: algorithm description and results. J. Appl. Meteor. Climatol., 47, 1175-1198.

Parol, F., J. C. Buriez, G. Brogniez, and Y. Fouquart, 1991: Information content of AVHRR channels 4 and 5 with respect to the effective radius of cirrus cloud particles. J. Appl. Meteor, 30, 973-984.

Platnick, S., K. G. Meyer, M. D. King, G. Wind, N. Amarasinghe, B. Marchant, G. T. Arnold, Z. Zhang, P. A. Hubanks, R. E. Holz, P. Yang, W. L. Ridgway, and J. Riedi, 2017: The MODIS cloud optical and microphysical products: Collection 6 updates and examples from Terra and Aqua. IEEE Trans. Geosci. Remote Sens., 55, 502-525.

Poulsen, C. A., R. Siddans, G. E. Thomas, A. M. Sayer, R. G. Grainger, E. Campmany, S. M. Dean, C. Arnold, and P. D. Watts, 2012: Cloud retrievals from satellite data using optimal estimation: evaluation and application to ATSR. Atmos. Meas. Tech., 5, 1889-1910.

Rienecker, M. M., M. J. Suarez, R. Gelaro, R. Toding, J. Bacmeister, E. Liu, M. G. Bosilovich, S. D. Schubert, L. Takacs, G.-K. Kim, S. Bloom, J. Chen, D. Collins, A. Conaty, A. da Silva, W. Gu, J. Joiner, R. D. Koster, R. Lucchesi, A. Molod, T. Owens, S. Pawson, P.
Pegion, C. R. Redder, R. Reichle, F. R. Robertson, A. G. Ruddick, M. Sienkiewicz, and J. Woollen, 2011: MERRA: NASA's modern-era retrospective analysis for research and applications. J. Climate, 24, 36243648.

Rodgers, C. D., 2000: Inverse Methods for Atmospheric Sounding: Theory and Practice. World Scientific, Singapore, $238 \mathrm{pp}$.

Saito, M., H. Iwabuchi, P. Yang, G. Tang, M. D. King, and M. Sekiguchi, 2017: Ice particle morphology and microphysical properties of cirrus clouds inferred from combined CALIOP-IIR measurements. J. Geophys. Res., 122, 4440-4462.

Schmit, T. J., M. M. Gunshor, W. P. Menzel, J. J. Gurka, J. Li, and A. S. Bachmeier, 2005: Introducing the next-generation Advanced Baseline Imager on GOESR. Bull. Amer. Meteor. Soc., 86, 1079-1096.

Sekiguchi, M., and T. Nakajima, 2008: A $k$-distributionbased radiation code and its computational optimization for an atmospheric general circulation model. $J$. Quant. Spectrosc. Radiat. Transfer, 109, 2779-2793.

Sourdeval, O., L. C.-Labonnote, G. Brogniez, O. Jourdan, J. Pelon, and A. Garnier, 2013: A variational approach for retrieving ice cloud properties from infrared measurements: Application in the context of two IIR validation campaigns. Atmos. Chem. Phys., 13, 82298244.

Sourdeval, O., L. C.-Labonnote, A. J. Baran, and G. Brogniez, 2015: A methodology for simultaneous retrieval of ice and liquid water cloud properties. Part I: Information content and case study. Quart. J. Roy. Meteor. Soc., 141, 870-882.

Waliser, D. E., J.-L. F. Li, C. P. Woods, R. T. Austin, J. Bacmeister, J. Chern, A. Del Genio, J. H. Jiang, Z. Kuang, H. Meng, P. Minnis, S. Platnick, W. B. Rossow, G. L. Stephens, S. Sun-Mack, W.-K. Tao, A. M. Tompkins, D. G. Vane, C. Walker, and D. Wu, 2009: Cloud ice: A climate model challenge with signs and expectations of progress. J. Geophys. Res., 114, D00A21, doi:10.1029/2008JD010015.

Walther, A., and A. K. Heidinger, 2012: Implementation of the daytime cloud optical and microphysical properties algorithm (DCOMP) in PATMOS-x. J. Appl. Meteor. Climatol., 51, 1371-1390.

Wang, C., S. Platnick, Z. Zhang, K. Meyer, and P. Yang, 2016: Retrieval of ice cloud properties using an optimal estimation algorithm and MODIS infrared observations: 1. Forward model, error analysis, and information content. J. Geophys. Res., 121, 5809-5826.

Watts, P. D., R. Bennartz, and F. Fell, 2011: Retrieval of two-layer cloud properties from multispectral observations using optimal estimation. J. Geophys. Res., 116, D16203, doi:10.1029/2011JD015883.

Yang, G.-Y., and J. Slingo, 2001: The diurnal cycle in the tropics. Mon. Wea. Rev., 129, 784-801.

Yang, P., L. Bi, B. A. Baum, K.-N. Liou, G. W. Kattawar, M. 
I. Mishchenko, and B. Cole, 2013: Spectrally consistent scattering, absorption, and polarization properties of atmospheric ice crystals at wavelengths from 0.2 to $100 \mu \mathrm{m}$. J. Atmos. Sci., 70, 330-347.
Zhang, Z., S. Platnick, P. Yang, A. K. Heidinger, and J. M. Comstock, 2010: Effects of ice particle size vertical inhomogeneity on the passiveremote sensing of ice clouds. J. Geophys. Res., 115, D17203, doi:10.1029/ 2010JD013835. 